\title{
Análise da gestão do cuidado no Programa de Saúde da Família: referencial teórico-metodológico
}

Analysis of managed-care in the Family Health Program: the methodologic and theory referential

Análisis de la gestión de la atención en el Programa de Salud de la Familia: referencial teórico-metodológico

\author{
Maria Raquel Gomes Maia Pires', Leila Bernardo Donato Göttems" \\ 'Universidade Federal de Minas Gerais. Escola de Enfermagem. Belo Horizonte, MG \\ "Universidade Católica de Brasilia. Brasília, DF
}

Submissão: $25 / 03 / 2008$

Aprovação: 24/01/2009

\section{RESUMO}

Nesta reflexão, Questiona-se Que referencial teórico-metodológico pode ser utilizado para analisar o potencial para autonomia do cuidado no processo de trabalho do PSF. Parte-se da premissa de que a análise do processo de trabalho em saúde centrado nas contradições da gestão do cuidado contribui para o desvelamento de potencialidades emancipatórias. Objetivos: discutir as contradições, possibilidades e desafios às mudanças da gestão do cuidado no Progrma de Saúde da Família/Atenção Básica/Sistema ùnico de Saúde e propor um referencial teórico-metodológico para análise da gestão do cuidado no processo de trabalho do Programa de Saúde da Família. Conclui-se pelo uso de referenciais Que explicitem se o cuidado em saúde tende mais para o domínio autoritário ou para o partilhamento de poderes entre os sujeitos, entendendo-os complementares.

Descritores: Programa Saúde da Família; Atenção Primária à Saúde; Gestão em Saúde

\section{ABSTRACT}

The theoretical-methodological referential is Questioned on the possibility of its use to analyze the potential of the Care autonomy in the working process of the Family Health Program. The premise is that the analysis of the health working process, centered on the contradictions of care management contributes for unveiling emancipating potentialities. Objectives: to discuss contradictions, possibilities and challenges to the care management changes in the Family Health Program/Primary Care/National Health System, and to propose a theoreticalmethodological referential for the analysis of the care management in the working process of Family Health Program. It is concluded that there should be used referential which explain if the health care tends more to the authoritarian dominium or to power sharing among the subjects, understanding them as complementary.

Descriptors: Family Health Program; Primary health care; Health management.

\section{RESUMEN}

En esta reflexión, se cuestiona cuál referencial teórico-metodológico puede ser utilizado para analizar el potencial para autonomía del cuidado en el proceso de trabajo del Progrma de Salud de la Familia. Se parte de la premisa de que el análisis del proceso de trabajo en salud, centrado en las contradicciones de la gestión del cuidado, contribuye para la identificación de potencialidades emancipadoras. Objetivos: discutir las contradicciones, posibilidades y desafíos en los cambios de la gestión del cuidado en Progrma de Salud de la Familia/Atención Primaria/Sistema Unico de Salud y proponer un referencial teórico-metodológico para análisis de la gestión del cuidado en el proceso de trabajo del Progrma de Salud de la Familia. Se concluye mediante el uso de referenciales que expliciten si el cuidado en salud tiende más para el dominio autoritario o para la división de poderes entre los sujetos, entendiéndolos como complementares.

Descritores: Programa salud de la familia; Atención primaria de salud; Gestión en salud. 


\section{INTRODUÇÃO}

Os desafios para Que o Programa Saúde da Família (PSF) se constitua em estratégia privilegiada de estruturação da atenção básica, com repercussões para o sistema de saúde, coincidem com as ambivalências do próprio SUS (Sistema Único de Saúde), ou seja, ampliar a Qualidade do acesso aos serviços de saúde da população, num contexto de mercantilização da saúde. A ambigüidade presente no Saúde da Família, ora viabilizando inovações na forma de gerir o cuidado em saúde, ora reproduzindo enfoques restritivos dos programas de saúde pública, centrados na epidemiologia das doenças de massas, figura como aspecto importante à discussão de mudança de modelo assistencial. Dentre as possibilidades à reorganização pretendida, destaque-se a produção de conhecimentos Que contribuam para a análise da gestão do cuidado no processo de trabalho dos profissionais de saúde. Entende-se por gestão do cuidado, como se verá a seguir, a forma com Que as relações intersubjetivas de ajuda-poder se organizam e se manifestam no processo de trabalho, conformando cenários mais próximos do domínio ou da emancipação do outro(1).

Nesse ensaio, Questiona-se Que referencial teórico-metodológico pode ser utilizado para analisar o potencial para autonomia do cuidado no processo de trabalho do PSF. Parte-se da premissa de Que a análise do processo de trabalho em saúde centrado nas contradições da gestão do cuidado contribui para o desvelamento de potencialidades emancipatórias. Noutros termos, Que o uso de referenciais Que explicitem as relações de poder presentes no cuidado, permeado de tensão entre a tutela e a libertação dos sujeitos, parece válido para indicar cenários de autonomia no âmbito do trabalho das Equipes Saúde da Família (ESF). Como objetivos, têm-se: a-discutir as contradições, possibilidades e desafios às mudanças da gestão do cuidado no PSF/Atenção Básica/SUS e bpropor um referencial teórico-metodológico para análise da gestão do cuidado no processo de trabalho do PSF.

Faz-se um aprofundamento contextual sobre a necessidade de mudar a lógica com Que se tem gerido os serviços e ações em saúde para atender as necessidades de saúde da população, tendo a Saúde da Família como eixo do reordenamento assistencial proposto, no nível da atenção básica/SUS. As especificidades desse programa/estratégia são abordadas, com destaque para as ambigüidades do trabalho em saúde e relações de cuidado envolvidas. A partir desse panorama, constroem-se algumas dimensões, Questões e parâmetros Qualitativos Que subsidiam a análise das relações de poder e autonomia presentes na gestão do cuidado em saúde.

\section{METODOLOGIA}

Ensaio teórico-metodológico Que sistematiza conceitos e abordagens centradas no método como caminho de construção do pensamento ${ }^{(2)}$. Aprofundam-se concepções e revisões bibliográficas para delimitação de parâmetros e Questões Que auxiliem na análise da gestão do cuidado no âmbito do trabalho do PSF. As fontes de informação foram revisões de literatura sobre o tema, bem como produções bibliográficas sobre as categorias trabalho e cuidado, construtos centrais do estudo. Levantou-se artigos científicos publicados e disponíveis nas bases de dados bilbiográficos, especialmente na BIREME e SciELO.

\section{RESULTADOS E DISCUSSÃO}

\section{Saúde da Família/Atenção Básica/SUS: entre a estratégia de} mudança e o programa de saúde pública

O Programa Saúde da Família surgiu em 1994 com o propósito de ampliar o acesso da população aos serviços básicos de saúde, numa conjuntura neoliberal Que põe em risco a universalidade do sistema de saúde brasileiro. Por outro lado, assume diretrizes consoantes com o SUS, ou seja, integralidade, resolutividade e intersetorialidade das ações, trabalho em equipe, vínculo de coresponsabilidade às famílias assistidas e estímulo à participação social, e se propõe como estratégia para a organização da rede básica de serviços de saúde, com repercussões para o sistema de saúde. Entre programa de saúde pública e a estratégia de mudança, Saúde da Família segue os dilemas do SUS, Qual seja, de pretenderse universal e igualitário, numa realidade neoliberal e com pouca cidadania organizada para exigir oportunidades de vida.

Adota-se aqui a terminologia programa/estratégia para caracterizar a ambivalência entre mudança e conservadorismo Que o PSF carrega, fruto da historicidade das políticas e modelos de atenção à saúde no Brasil. Acrescente-se Que QualQuer linearidade entre a noção de programa ou estratégia é restritiva, porque ambas se precisam para negarem-se numa dimensão transformadora. Ou seja, a mudança pretendida tanto precisa das normas, diretrizes e ordenações, como aQuelas presentes na atual Política Nacional de Atenção Básica $^{(3)}$, Quanto da negociação, flexibilidade, confronto e criatividade, inerente às ações de organização dos serviços no sistema de saúde.

Cabe situar o PSF no contexto de mudança das práticas de saúde à luz de princípios eqüânimes, ponderando sobre os desafios à (re)organização da atenção básica como premissa estruturante de sistemas de saúde mais democráticos e acessíveis. Noutros termos, discutir se as possibilidades de mudanças na gestão da atenção básica/SUS, tendo por eixo o Saúde da Família, se afinam mais aos interesses econômicos de focalização de políticas públicas de cunho neoliberal, conformando-se em meros programas de saúde pública para pobres, ou às prerrogativas cidadãs de saúde como bem-comum, traduzidas pela idéia de estratégia reorganizadora do modelo de atenção à saúde - forma com Que serviços e práticas de estruturam e disputam espaços para assistir à saúde da população, num determinado contexto sócio-histórico ${ }^{(4)}$.

As versões atuais de organização da atenção básica à saúde/ SUS evidenciadas a partir da implantação do programa/estratégia SF concentram um misto de avanço e retrocesso. Além da clássica influência do autoritarismo e controle das epidemias remanescente do sanitarismo da década de 30, os discursos de Que é preciso planejar os serviços a partir das necessidades e do perfil epidemiológico da população, a idéia da rede básica como 'porta de entrada' do usuário, Que pode ter seu problema resolvido ali ou ser encaminhado para outros níveis de atenção, a visão de regionalização e descentralização dos serviços, apenar de pertinentes, apresentam características restritivas das produções sobre atenção básica e planejamento em saúde ${ }^{(5,6)}$. O risco, no caso da organização hierarquizada e descentralizada do SUS, é Que a maquiagem de racionalidade do sistema se misture com os 
limites contingenciais do gasto em saúde, sob um discurso tecnicamente pertinente e com pouca articulação tripartite entre os níveis de governo, fragmentando a gestão do SUS ${ }^{(7)}$. Ademais, a concepção de 'porta de entrada', tende a deixar o usuário esperando para adentrar no que lhe é de direito, denotando visão restrita de saúde ao adotar o continuum da História Natural da Doença, de tom cartesiano ao supor Que a doença segue um curso linear, com início, meio e fim.

Por outra, as perspectivas do PSF como estratégia para reorganizar os serviços e práticas de saúde na atenção básica, com repercussões para o SUS, operando principalmente na micropolítica do trabalho em saúde, coadunam com correntes teóricas de vanguarda, pautadas no paradigma da vigilância à saúde e interdisciplinariedade ${ }^{(4,7-8)}$. A grande capilaridade Que o SF atinge, associada aos desafios gerados pelo rápido crescimento Quantitativo, descompassado da devida Qualidade necessária à consecução das diretrizes éticas Que o programa/estratégia assume, talvez seja avanço e retrocesso da proposta. É virtude porQue a rápida expansão virou fato político no interior do SUS difícil de ser ignorado, forjando debates sobre o modelo tecno-assistencial, a necessidade de mudar a formação dos profissionais e a forma de produzir cuidados em saúde. Fragiliza-se Quando reforma vestígios da saúde pública brasileira, embalados pelo conservadorismo neoliberal de se constituir em ação compensatória de baixo custo para grupos focalizados e marginalizados do acesso a serviços de saúde de Qualidade $^{(6)}$.

O potencial de mudança do Saúde da Família reside tanto nas diretrizes Que norteiam o processo de trabalho dos profissionais Quanto na reorganização de serviços e práticas Que ele pode ensejar. Ao delimitar o território como lócus de atuação da Equipe Saúde da Família (ESF), pautada no trabalho em equipe e no vínculo de coresponsabilidade com a população, pode organizar os serviços de saúde a partir da priorização dos problemas identificados, contribuindo para a organização da demanda aos demais pontos da rede de atenção. Dessa forma, além do fortalecimento de vínculos entre os sujeitos, responsabilizações partilhadas e promoção da autonomia, se a ESF estiver inserida num processo de educação, contar com condições adequadas de trabalho, bem como uma rede de média e alta complexidade do sistema de saúde operante, pode melhorar consideravelmente o acesso da população aos serviços. Entende-se por acesso a perspectiva ampla de atendimento às reais necessidades dos cidadãos, ou o Quanto mais próximo disso os serviços conseguem se organizar, ampliando a acessibilidade dos $\operatorname{mesmos}^{(9)}$.

Valem algumas ponderações sobre as possibilidades de mudanças na forma de organização das práticas dos profissionais de saúde, do qual o SF assume protagonismo crescente. No Que se refere ao processo de trabalho, a dimensão da equipe e a abordagem à família são aspectos ainda distantes do cotidiano da maioria das ESF. Nesse aspecto, observa-se Que a recente 'Política da Atenção Básica'3 avança pouco, uma vez Que concebe a família como 'estrutura e funcionalidade', concepção eivada da racionalidade clínica do normal/patológico, com pouco espaço para o multiculturalismo, respeito à diversidade de saberes e amplas abordagens à dinâmica da vida familiar. Essa característica tem raízes no paradigma biomédico, repercutindo na formação e prática dos profissionais. O foco na doença, nos procedimentos dissociados do contexto Que os produzem e a visão linear do processo saúde-doença dominam o perfil de grande parte dos profissionais da ESF, fruto da formação tecnicista e pouco crítica ${ }^{(10,1)}$.

O entendimento uno/múltiplo ${ }^{(12)}$ da família, enQuanto síntese da diversidade de afetos, tensões e contradições Que o cuidar assume no espaço privado e doméstico das relações sociais, passa ao largo das práticas dos profissionais de saúde. Da mesma forma, a busca pela interdisciplinaridade nos processos de trabalho, Que se interpenetram para conjugar novas abordagens à saúde da população, constituem vivências esporádicas e sem maior expressão no trabalho do Saúde da Família/SUS. Em geral, há dificuldades em lidar com as subjetividades, porque os instrumentos, saberes e tecnologias apreendidas na formação e prática desses profissionais se encerram na racionalidade moderna, aprisionadora de sentidos ${ }^{(13)}$.

A despeito desse cenário pouco inovador, inscrito na própria conjuntura da política de saúde brasileira que o PSF apenas revela com maior amplitude, não sendo responsável direto por ele, há avanços significativos. Diversas experiências de gestões municipais conseguiram reordenar seus sistemas de saúde a partir do SF, tornando-os mais acessíveis e hierarquizados ${ }^{(14)}$. Dignos de nota são os vínculos estabelecidos entre profissionais e população Que, se o modelo hospitalocêntrico há muito rompeu, o SF vem conseguindo restaurar com belíssimos relatos. A mobilização das redes de solidariedade local e a forte penetração Que o programa/ estratégia consegue obter, adentrando no espaço privado das relações familiares, é outro forte componente do trabalho da ESF. Poder-se-ia dizer que o avanço Que o Saúde da Família melhor oportuniza se insere na interação do trabalho da equipe, onde o ato de cuidar se imiscui das diversidades de saberes Que permeiam o lócus privilegiado de atuação da ESF, a comunidade. Dessa forma, o programa/estratégia Saúde da Família pode interferir na produção do cuidado em saúde, em âmbito individual ou coletivo, revelando as congruências e contradições inerentes à prática social.

Apesar do processo de trabalho das ESF ser fundamental para a mudança requerida, podendo revelar interações de cuidado transformadoras, não é suficiente. Há de se levar em conta os cenários Que propiciam, emperram, despertam ou embrutecem tais interações disruptivas. A precariedade das relações de trabalho, as inioüidades sociais, a conjuntura econômica, as condições insalubres, os cenários de violência, as influências políticas locais, bem como as debilidades na formação dos profissionais, fazem parte da lógica capitalista Que tem produzido retrocessos e avanços na política de saúde. A ousadia do Saúde da Família reside na contribuição à mudança na forma de gerir o cuidado em saúde, mesmo sendo programa Que se assume como estratégia para reorganizar os serviços de saúde/SUS. Nesse sentido, tanto pode sucumbir à rigidez da norma programática focalizada e seletiva, como pode conformar relações de poderes mais democráticas.

\section{Gestão do Cuidado e Trabalho em Saúde: conceitos para a análise}

Cabe ponderar sobre as especificidades e semelhanças existentes entre cuidado e trabalho em saúde, no sentido de clarear os construtos analíticos. Embora o cuidar, enQuanto interação e disrupção reconstrutora de subjetividades espoliadas, revele-se mais facilmente no encontro Que se estabelece entre profissionais e usuários, ele não coincide com o processo de trabalho em saúde. Entenda-se cuidado, em sentido ontológico, uma angústia libertária 


\begin{tabular}{|c|c|c|}
\hline Dimensão & Questões Analíticas & Parâmetros de Qualidade \\
\hline $\begin{array}{l}\text { Conjuntura do } \\
\text { Cuidado }\end{array}$ & $\begin{array}{l}\text { Qual a conjuntura em Que são } \\
\text { geradas as relações de ajuda- } \\
\text { poder no âmbito da ESF? }\end{array}$ & $\begin{array}{l}\text { - Política de saúde em Que o PSF se insere segue princípios e diretrizes } \\
\text { consensuados na esfera pública e contempla a ampliação da participação da } \\
\text { sociedade civil (cidadania). } \\
\text { - Os profissionais das ESF se preocupam em conhecer/compreender a } \\
\text { conjuntura da política para melhor decidir/gerir cenários de cuidado à saúde. } \\
\text {-Inserção da ESF na UBS ocorre de forma priorizada, traduzida na autonomia } \\
\text { e partilhamento de decisões. } \\
\text {-Ações intersetoriais permeam o cotidiano da ESF, constituindo-se em } \\
\text { espaço dialogado de saber. } \\
\text {-Ações da ESF se organizam a partir da análise das forças sociais, com } \\
\text { avaliações, reprogramações e controle democrático delineado. }\end{array}$ \\
\hline $\begin{array}{l}\text { Relações Inter- } \\
\text { institucionais }\end{array}$ & $\begin{array}{l}\text { Como os atores Que fazem } \\
\text { parte da ESF se articulam e } \\
\text { disputam espaços na } \\
\text { conformação das relações de } \\
\text { ajuda-poder? }\end{array}$ & $\begin{array}{l}\text {-Contexto em Que a ESF se insere é entendido como correlações de forças } \\
\text { pelos atores. } \\
\text {-Panorama das forças sociais Que influenciam a ESF é constantemente } \\
\text { analisado no processo decisório dos profissionais. } \\
\text {-Efetivo Controle Democrático (de baixo para cima): proposições } \\
\text { demandadas pela comunidade são atendidas pela ESF. } \\
\text {-Democratização de poderes:decisões da ESF é discutida com a comunidade, } \\
\text { para além do ACS. }\end{array}$ \\
\hline $\begin{array}{l}\text { Ajuda-poder entre } \\
\text { os sujeitos }\end{array}$ & $\begin{array}{l}\text { O PSF tem propiciado o } \\
\text { resgate da autonomia dos } \\
\text { sujeitos nas ações Que realiza? } \\
\text { O cuidado no processo de } \\
\text { trabalho do PSF tende mais } \\
\text { para o domínio autoritário ou } \\
\text { libertação de sujeitos? }\end{array}$ & $\begin{array}{l}\text {-Profissionais das ESF têm nível de governabilidade e realização elevado das } \\
\text { ações propostas. } \\
\text {-Os princípios e diretrizes do PSF se traduzem em objetivos alcançados e } \\
\text { constantemente avaliados/reprogramados pela ESF. } \\
\text {-ESF gerencia oferta de serviços para captar de forma mais ampla as } \\
\text { necessidades da população, para além do enfoQue biomédico. } \\
\text {-As ações da ESF ocorre a partir da demanda/necessidades da população, de } \\
\text { informações sistematizadas e em diálogo com as forças sociais. } \\
\text {-Gestão da ajuda-poder centra-se no usuário e oportunizaria cenários onde a } \\
\text { autonomia se manifesta (construção de projetos próprios, clínica ampliada, } \\
\text { diálogo com os saberes locais, partilhamento de condutas clínicas e ações } \\
\text { coletivas). }\end{array}$ \\
\hline
\end{tabular}

Quadro 1. Gestão do cuidado no trabalho do PSF - referências metodológicas para identificação de cenários de autonomia e poder.

sobre a existência e dimensão articuladora de si ${ }^{(15)}$. Para os propósitos desse texto, a gestão do cuidado no processo de trabalho em saúde é entendida como forma com Que o cuidar se revela e se organiza na interação propiciada entre sujeitos, podendo gerar interações e subversões potencialmente emancipatórias ou restritivas das múltiplas liberdades humanas.

Um debate oportuno para subsidiar as mudanças nas práticas dos profissionais de saúde, tornando-as mais reconstrutoras de cidadanias, diz respeito a necessidade de alterar a excessiva tecnificação Que o cuidado sofre no processo de trabalho. Tal aprisionamento do cuidado é expresso pela ultra-especialização alienante do todo, pelo modo mecanicista de produzir serviços e ações em saúde, bem como pela inibição das autonomias presente na relação Que se estabelece no ato de cuidar. Em seu oposto, aposta-se Que a politicidade do cuidado, entendida como relação dialética entre ajuda e poder para a construção da autonomia relativa de sujeitos, sejam esses usuários, profissionais, técnicos ou gestores do SUS, possa subsidiar relações mais democráticas de poder ${ }^{(1,16)}$. Tal cuidar assume aspectos para além da produtividade do trabalho em saúde, envolvendo as dimensões ecológica, epistemológica, ontológica, social e política Que caracterizam o viver. Pode ainda ser vislumbrado como mediação intersubjetiva entre a tutela e a emancipação, onde a desconstrução de assimetrias de poder em favor da liberdade ocorre pelas vias do confronto e superação, em constante vir-a-ser.

Por outro lado, o fazer corporificado na categoria trabalho, em perspectiva dialética histórico-estrutural, requer um objeto em Que se operam os meios para se obterem os bens e serviços, necessitando da essência genérica humana e alienando-a dos sujeitos Que a produzem $^{(17)}$. No caso da saúde, onde o trabalho é consumido no ato da produção como 'trabalho-vivo-em-ato'(18), as semelhanças com o cuidado intensificam-se porque ocorre encontro intersubjetivo para produção social da saúde. Contextualmente, tal discussão se insere nas transformações pelas Quais tem passado as relações de trabalho em tempos globais e transnacionalização dos mercados. O capitalismo atual necessita muito mais do conhecimento humano para gerar valor e acumulação (mais-valia relativa) do Que propriamente habilidade manual e bens duráveis (mais-valia absoluta) ${ }^{(19)}$. Tais mudanças têm resignificado as relações entre trabalho e tempo livre, por exemplo, uma vez que atividade criativa não segue o ritmo fabril, necessitando de outros elementos subjetivos para se inovar, como inspiração, motivação, informação e emoções $^{(20)}$. Nesse sentido, o imaterial pode coincidir com a própria vida (expressão de cuidado), forjando-se no trabalho enQuanto 
extensão do humano. Mesmo por essas vias, o cuidado emerge como traço ontológico, político, ecológico e epistemológico, posto tratar-se de um modo-de-ser ${ }^{(2 \mathrm{l})}$, conviver e se modificar inerente aos seres vivos, para além do próprio humano.

Advoga-se que politicidade do cuidado - expresso pelo triedro conhecer para cuidar melhor, cuidar para confrontar, cuidar para emancipar - pode se constituir em referência analítica para a gestão do cuidado em saúde ${ }^{(22)}$. O triedro do cuidar articula sinteticamente as categorias conhecimento, poder e emancipação numa perspectiva epistemológica, ética e política. Se aposta num conhecimento que torne possíveis relações de ajuda-poder igualitárias, Que faça emergir as contradições da arena política, numa perspectiva fortalecedora de sujeitos históricos.

À guisa de um Quadro analítico para a gestão do cuidado, poderse-ía articular o 'conhecer para cuidar melhor' com o contexto em Que as forças sociais se configuram na política de saúde, da Qual o PSF faz parte. Ou seja, na forma com Que são geradas as ações da política pública, na inserção dos atores estratégicos, nas definições ou indefinições governamentais, nas condições sociais e econômicas Que interferem nas relações intersubjetivas. Desse diálogo propõe-se a dimensão 'conjuntura do cuidado', cujo Questionamento focaliza a conjuntura em Que são geradas as relações de ajuda-poder no âmbito da ESF. Num segundo movimento, o 'cuidar para confrontar' revela as relações de poder em Que o trabalho em saúde se insere no contexto histórico-social. Diz respeito aos atores Que fazem parte da política, a participação e organização da sociedade civil, suas articulações, interesses, correlações de forças e significados. Trata-se da segunda dimensão, 'relações interinstitucionais', Que Questiona como os atores Que fazem parte da ESF se articulam e disputam espaços na conformação das relações de ajuda-poder. A partir da conjuntura do cuidado e relações de poderes reveladas, propõe-se o resgate da autonomia de sujeitos para a construção de projetos próprios, permeada por relações de cuidado. Surge daí a terceira dimensão, ajuda-poder entre os sujeitos, cujo foco é perguntar se o trabalho do PSF tem propiciado maior oportunidade e liberdade de escolha nas ações Que realiza. O Quadro I sistematiza o Que se vem discutindo. Sugere-se que tal referencial possa ser utilizado em investigações científicas, na educação ou como diretrizes capazes de orientar a gestão do cuidado no trabalho dos profissionais.

\section{CONCLUSÃO}

De modo geral, a literatura aponta avanços e retrocessos no processo de trabalho do PSF. As atitudes de rígida disciplina, verticalidade na abordagem à saúde, massificação de condutas, visão reduzida do processo saúde-doença e foco na 'doença coletiva' influenciam fortemente as práticas desenvolvidas, mesmo naquelas com potencial para mudanças. Ao mesmo tempo, observa-se inegável poder de mobilização desse programa/estratégia, capaz de influencia dinâmicas tanto da área de abrangência, como do sistema de saúde. Esse traço, aliado ao vínculo de cuidado Que desenvolve com a população Que atende, constitui o principal trunfo das ESF, sendo capaz de influir tanto nos espaços domésticos das relações privadas, Quanto agora da cidadania pública e negociada.

Considerando os desafios colocados para que o Saúde da Família se viabilize enquanto estratégia (re)ordenadora de relações de domínio, seja no âmbito da articulação entre serviços e níveis de atenção do SUS, seja no escopo da produção das ações em saúde (processo de trabalho), a politicidade do cuidado (gestão da ajudapoder na construção da autonomia de sujeitos) aparece como alternativa importante para orientar a ampliação de cidadanias. Nesse sentido, referenciais teórico-metodológico Que contribuam para análise da gestão do cuidado no processo de trabalho do Saúde da Família, com foco na autonomia dos sujeitos envolvidos (sejam esses técnicos, gestores, profissionais de saúde, usuários ou comunidade), pode revelar as excentricidades, contradições, avanços e retrocessos desse programa/estratégia. Dentre outros aspectos, é possível verificar se o cuidado no processo de trabalho dos profissionais tende mais para o domínio autoritário ou para o partilhamento de poderes, entendendo-os complementares.

\section{REFERÊNCIAS}

I. Pires MRGM. Politicidade do cuidado e processo de trabalho em saúde: conhecer para cuidar melhor, cuidar para confrontar, cuidar para emancipar. Ciênc Saúde Coletiva 2005; 10(4): 1025-35.

2. Minayo MCS, Deslandes SF. Caminhos do Pensamento: epistemologia e método. Rio de Janeiro: Fiocruz; 2002.

3. Ministério da Saúde (BR). Portaria GM/MS n. 648. Política Nacional da Atenção Básica. Diário Oficial da União 2006 mar.

4. Paim IS. Desafios para a saúde coletiva no século XXI. Salvador: EDUFBA; 2006

5. Merhy EE. A rede básica como uma construção da saúde pública e seus dilemas. In: Merhy EE. Agir em saúde - um desafio para o público. 2a ed. São Paulo: Hucitec; 2002.

6. Gadelha CAG. Desenvolvimento e saúde: em busca de uma nova utopia. Saúde em Debate 2005; 29(71): 327-38.

7. Campos GWS, Donitti AC. Apoio Matricial e equipe de referência: uma metodologia para a gestão do trabalho interdisciplinar em saúde. Cad Saúde Pública 2007; 23(2): 399-407.
8. Campos GWS. Clínica e saúde coletiva compartilhadas: teoria Paidéia e reformulação ampliada do trabalho em saúde. In: Campos GWS. Tratado de saúde coletiva. São Paulo: Hucitec; 2006.

9. Travassos C, Martins M. Uma revisão sobre os conceitos de acesso e utilização de serviços de saúde. Cad Saúde Pública; 2004; 20(Supl 2):190-8.

10. Pires D. Reestruturação produtiva e trabalho em saúde no Brasil. São Paulo: CUT/Annablume; 1998.

I I. Rezende ALM. Saúde: dialética do pensar e do fazer. São Paulo: Cortez; 1989.

12. Morin E. Método 5 - A humanidade da humanidade. Porto Alegre: Sulina; 2002.

13. Bauman Z. Modernidade líeuida. Rio de Janeiro: Zahar Editores; 2001.

14. Ministério da Saúde (BR). Secretaria de Assistência à Saúde. Secretaria de Gestão dos Investimentos em Saúde. Experiências inovadoras do SUS. Brasília: Ministério da Saúde; 2002. 
15. Heidegger M. Ser e tempo. Parte 1. 12 $2^{\mathrm{a}}$ ed. Petrópolis: Vozes; 2002.

16. Pires MRGM. Politicidade do Cuidado como referência emancipatória para a enfermagem: conhecer para cuidar melhor, cuidar para confrontar, cuidar para emancipar. Rev Latino-am Enfermagem 2005; 13(5): 729-36.

17. Marx K. O trabalho alienado. In: Economia política e filosofia. Rio de Janeiro: Melso; 1963.

18. Merhy EE. SUS e um de seus dilemas: mudar a gestão e a lógica do processo de trabalho em saúde (um ensaio sobre a macropolítica do trabalho vivo) In: Fleury S, organizador. Saúde e democracia - a luta do CEBES. São Paulo: Lemos editorial; 1997.

19. Gorz A. O imaterial - conhecimento, valor e capital. São Paulo: Annablume; 2005.

20. De Mais D. Ócio criativo. Rio de Janeiro: Sextante; 2000.

21. Boff L. Saber Cuidar - etica do humano. São Paulo: Vozes; 1999.

22. Pires MRGM. Politicidade do Cuidado e Avaliação em Saúde: instrumentalizando o resgate da autonomia de sujeitos no âmbito de programas e políticas de saúde. Rev Bras Saúde Matern Infant 2005; 5 (supl I): S7 I-S8 I 